\title{
Reply to Complexity Analysis of Respiratory Dynamics
}

Cindy Thamrin ${ }^{1}$, Urs Frey ${ }^{2}$, David A. Kaminsky ${ }^{3}$, Helen K. Reddel ${ }^{1}$, Andrew J.E. Seely ${ }^{4}$, Béla Suki ${ }^{5}$, and Peter J. Sterk ${ }^{6}$

${ }^{1}$ Woolcock Institute of Medical Research and Sydney Medical School, University of Sydney, Australia;

${ }^{2}$ University Children's Hospital Basel, Switzerland;

${ }^{3}$ University of Vermont College of Medicine, Burlington, Vermont;

${ }^{4}$ Ottawa Hospital Research Institute, University of Ottawa, Ontario, Canada;

${ }^{5}$ Department of Biomedical Engineering, Boston University, Boston, Massachusetts;

${ }^{6}$ Academic Medical Centre, University of Amsterdam, Amsterdam, The Netherlands.

\section{Corresponding author:}

Dr. Cindy Thamrin

Airway Physiology and Imaging Group

Woolcock Institute of Medical Research

PO Box M77, Missenden Road NSW 2050, Australia

(E) cindy.thamrin@woolcock.org.au 


\section{Letter to the editor:}

We thank Dr. Raoufy and colleagues for their interest [Raoufy et al, AJRCCM 2016] in our Pulmonary Perspective article(1). While we were not able to cover all aspects of the vast literature on complex systems, the concept of controllability(2) is indeed one of considerable interest, resulting in either too much or too little regularity in complex systems. Such observations have implications not only for better understanding of the underlying system, but also as a potential means of assessing control or stability of disease. In fact, previous work in infants has provided physiological insight into how control of breathing evolves with maturation(3-5), not least the remarkable ability of the respiratory system to reset itself to a former state of control, manifest as a decrease in short-range correlation when control goes awry(6).

In terms of adoption into clinical practice, the application of these ideas to study the breathing pattern may translate most readily to the intensive care unit or sleep clinic setting, where continuous monitoring of breathing is the norm. While monitoring of breathing is as yet uncommon in the clinical management of asthma, the work of Shirazi et al(7) and Raoufy et al(8) particularly in patients with well-controlled versus uncontrolled asthma suggest that such analyses may also be useful within this context. The advent of widely available portable or wearable health monitoring devices may further strengthen these applications.

Furthermore, the authors' use of machine learning methods to aid classification(8) enables one to objectively take into account the large number of dimensions necessary to assess complex systems, and ascribe importance to variables which have high predictive value and discard those which do not. It could be argued that such 
classification methods are of limited use as they are based on empirical or phenomenological observations rather than physiological understanding of the underlying pathology. However, they are valuable for hypothesis generation, and should always be affirmed by clinical intuition and practicability. More relevant to the present context, identification of highly ranked variables derived from complexity analyses would allow us to deduce whether or not controllability or adaptability are important features in respiratory disease. This would provide further validation for the clinical utility of the systems approach.

\section{References}

1. Thamrin C, Frey U, Kaminsky DA, Reddel HK, Seely AJ, Suki B, et al. Systems Biology and Clinical Practice in Respiratory Medicine. The Twain Shall Meet. Am J Respir Crit Care Med. 2016;194(9):1053-61.

2. Liu YY, Slotine JJ, Barabasi AL. Controllability of complex networks. Nature. 2011;473(7346):167-73.

3. Frey U, Silverman M, Barabasi AL, Suki B. Irregularities and power law distributions in the breathing pattern in preterm and term infants. J Appl Physiol (1985). 1998;85(3):789-97.

4. Cernelc M, Suki B, Reinmann B, Hall GL, Frey U. Correlation properties of tidal volume and end-tidal $\mathrm{O} 2$ and $\mathrm{CO} 2$ concentrations in healthy infants. J Appl Physiol (1985). 2002;92(5):1817-27.

5. Engoren M, Courtney SE, Habib RH. Effect of weight and age on respiratory complexity in premature neonates. J Appl Physiol (1985). 2009;106(3):76673.

6. Baldwin DN, Suki B, Pillow JJ, Roiha HL, Minocchieri S, Frey U. Effect of sighs on breathing memory and dynamics in healthy infants. J Appl Physiol (1985). 2004;97(5):1830-9.

7. Shirazi AH, Raoufy MR, Ebadi H, De Rui M, Schiff S, Mazloom R, et al. Quantifying memory in complex physiological time-series. PLoS One. 2013;8(9):e72854.

8. Raoufy MR, Ghafari T, Darooei R, Nazari M, Mahdaviani SA, Eslaminejad AR, et al. Classification of Asthma Based on Nonlinear Analysis of Breathing Pattern. PLoS One. 2016;11(1):e0147976. 